\title{
Volver para reconstruir el territorio y dignificar la vida: la experiencia del Consejo Comunitario de la Cuenca del Río Cacarica
}

\author{
Return to Rebuild the Territory and Dignify Life: The Experience \\ of the Community Council of the Cacarica River Basin
}

\author{
Wisthon Abadía \\ Universidad de Antioquia, Colombia
}

DOI: $10.22380 / 2539472 X .808$

\begin{abstract}
RESUMEN
Este artículo presenta las acciones que las comunidades del Consejo Comunitario de la Cuenca del Río Cacarica en el Bajo Atrato chocoano realizan para reconstruir su territorio y dignificar sus vidas, luego de haber sido víctimas de desplazamiento forzado en 1997. A través de procesos organizativos, de retorno y reconstrucción, las comunidades elaboran nuevas territorialidades, resignifican y rehacen sus vidas. Estas acciones emergen de la puesta en marcha de saberes externos y propios sobre la identidad y los derechos de estas comunidades, que les permiten resistir al modelo de "desarrollo" y las acciones bélicas que ocasionaron su desplazamiento.
\end{abstract}

Palabras claves: afrodescendientes, derechos colectivos, desplazamiento, identidad.
ABSTRACT

This article presents the actions that the communities from the Community Council of the Cacarica river basin, Bajo Atrato, Chocó, carry out to rebuild their territory and dignify their lives, after being victims of forced displacement in 1997. Through organization, return, and reconstruction processes communities develop new territorialities, re-signify and rebuild their lives. These actions emerge from the implementation of external and personal knowledge about identity and rights of these communities, which enable them to resist the logics of "development" that caused their displacement.

Keywords: Afro-descendants, collective rights, displacement, identity. 


\section{Introducción}

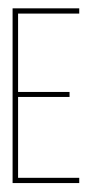

n este artículo busco dar cuenta de las estrategias desarrolladas por las comunidades del Consejo Comunitario de la Cuenca del Río Cacarica $^{1}$ (CCCRC) para defender la vida y el territorio. Resalto la importancia de la acción colectiva y el fortalecimiento de la gobernanza como eje central de las acciones de resistencia con las que hacen frente a los modelos de desarrollo moderno-colonial, y que les permiten a las comunidades reelaborar y resignificar saberes locales relacionados con la identidad, el territorio y el proyecto de vida colectivo.

Mi experiencia con algunas de las comunidades del CCCRC y otras en el Bajo Atrato se construyó a partir de mis estudios en antropología en la región de Urabá, un proceso de formación con reflexiones situadas en la región. Esa relación se reforzó al vincularme como funcionario de Parques Nacionales Naturales desde el año 2014 en otras regiones del Chocó y desde el 2016 en el Bajo Atrato, jurisdicción de los municipios de Turbo (Antioquia), Unguía y Riosucio (Chocó). El primer acercamiento a la región desembocó en la construcción de lazos con las comunidades en el Bajo Atrato y la posibilidad de acompañar algunos de sus procesos político-organizativos. Construir relaciones con las comunidades desde escenarios traslapados que tienen que ver con mi identidad y autorreconocimiento como hombre negro, pero a la vez con la investidura de funcionario estatal y como académico, ha sido una gran posibilidad para reflexionar con las comunidades desde varios escenarios sus-nuestras realidades sociales en las que se entrecruzan asuntos como la identidad, el racismo y el conflicto armado, y en donde nos permitimos reconocernos como distintos pero no distantes.

El análisis presentado en las siguientes páginas hace parte de los resultados del proyecto de investigación "Formas otras de promover la salud: protegiendo la vida, recuperando la tierra y reconstruyendo el territorio", desarrollado entre los años 2017 y 2019 como requisito para optar al título de magíster en Salud Pública de la Universidad de Antioquia. Fue un estudio etnográfico con perspectiva decolonial ${ }^{2}$ realizado en la comunidad de Bijao, perteneciente al

1 Los consejos comunitarios son autoridades étnico-territoriales reconocidas bajo el amparo de la Ley 70 de 1993 que tienen entre sus funciones principales administrar el territorio colectivo de comunidades negras y, según el Decreto 1745 de 1995, están constituidos por una asamblea general y una junta de gobierno.

2 Los estudios decoloniales son una propuesta epistemológica bajo la cual se identifican las formas de dominación estructuradas por la modernidad/colonialidad, que se basan principalmente en la configuración de patrones de poder eurocéntricos, que construyen realidades inequitativas, injustas y violentas de unos grupos humanos sobre otros. Para mayor 
CCCRC, mediante observaciones de campo, entrevistas semiestructuradas, talleres participativos y conversaciones, además de reflexiones surgidas del trabajo conjunto con las comunidades del Bajo Atrato en años anteriores.

El manuscrito sigue esta estructura: inicialmente presenta el contexto del CCCRC y algunos aspectos generales sobre la experiencia de violencia y desplazamiento forzado en la cuenca. Después, ahonda en las acciones desarrolladas por las comunidades del CCCRC para fortalecer los procesos organizativos y el liderazgo que se gesta en torno de la defensa del territorio en el marco de la creación, reestructuración o articulación de las organizaciones de base. Finalmente, presenta las labores emprendidas para crear las condiciones básicas que permitan el retorno de la población y los significados del territorio y el proyecto de vida colectivo que sustentan y dan sentido a la reconstrucción y reordenamiento de los modos de habitar ese espacio afectado por el conflicto armado, e imaginar estrategias para volver a hacer la vida.

\section{El Consejo Comunitario de la Cuenca del Río Cacarica (CCCRC)}

Sobre la ribera del río Atrato, en jurisdicción del municipio de Riosucio (Chocó), está ubicado el CCCRC. El territorio colectivo comprende la cuenca del río Perancho, que vierte sus aguas al Atrato, y las cinco subcuencas (Balsas, Bijao, La Raya, Peranchito y Perancho), en las que están ubicadas las veintitrés comunidades y dos zonas humanitarias ${ }^{3}$. Los botes, lanchas, canoas y pangas son el transporte obligatorio de la gente de este territorio que, por condiciones de salud, intercambios comerciales o gestiones políticas - entre otros motivos-, viaja por vía fluvial hacia Turbo o Riosucio, desde donde se conecta con ciudades como Quibdó y Medellín.

El CCCRC limita con Panamá y hace parte de un paisaje de gran diversidad biológica y cultural, “un complejo panorama de biodiversidad”, según acuñó el movimiento de comunidades negras en el país, que entiende la biodiversidad

claridad se recomienda revisar los trabajos de Castro-Gómez y Grosfoguel (2007), Restrepo y Rojas (2010), Rincón, Millán y Rincón (2015) y De Sousa Santos (2010).

3 Las zonas humanitarias son territorios constituidos como zonas de protección, en donde las comunidades se declaran actores neutros en el marco del conflicto armado e impiden el ingreso de los diferentes actores que promueven este tipo de violencia. 
como el resultado de sumar la cultura y el territorio. A diferencia de otros consejos comunitarios en el Pacífico, pero al igual que otros del Bajo Atrato, el Cacarica está habitado por familias negras y mestizas que llegaron a la zona desde 1930 en busca de "tierras sin hombres para hombres sin tierra" (Mininterior 2017), especialmente desde los ríos San Juan y Baudó, o por el auge comercial generado por la explotación de recursos naturales, desde la raicilla hasta la madera que se mantiene como una fuente importante de la economía regional. A esto se suma la circulación de mercancías entre el Caribe, el interior del país y el interior del Chocó, como parte de la economía regional que impulsó el asentamiento de familias en la cuenca del Cacarica. A partir de la década de 1990 la llegada de los mestizos, conocidos como chilapos, obedece principalmente a los procesos de migración ocasionados por el conflicto armado ocurrido en las sabanas de Córdoba y el Urabá antioqueño, que obligó a decenas de familias a buscar refugio en las selvas del Darién.

Debido a la rica biodiversidad, el Cacarica padece de lo que Rosero (2002), citando al líder social Naka Mandinga, denomina "la desgracia de la buena suerte”. Es decir, la desgracia de tener que enfrentar los intereses nacionales e internacionales de instituir en la región megaproyectos que ponen en riesgo la vida. En el Bajo Atrato esta desgracia ha estado asociada a la explotación maderera, a los planes de construcción del canal interoceánico Atrato-Truandó, a la construcción de la carretera Panamericana que conectaría el norte con el sur de América, a la siembra de palma aceitera y al cultivo de coca (Avella 2016). El conflicto armado en esta región, asociado en algunos casos con estos intereses, desembocó en el desplazamiento masivo de miles de personas en 1997 — hecho por el cual la Corte Interamericana de Derechos Humanos responsabilizó al Estado colombiano- (Corte IDH 2013). También es la razón por la que las comunidades han tenido la necesidad de emprender diferentes luchas por la defensa de sus vidas y su territorio.

\section{Vulneración de los derechos humanos. El desplazamiento forzado de 1997}

El contexto de violencia en el Bajo Atrato se remonta a sus relaciones con el Urabá antioqueño, donde a principios de los años 1990 grupos guerrilleros y paramilitares se disputaron el control del territorio que desde hace décadas ha sido aprovechado para la ganadería y la producción de banano y palma de aceite. Esa 
disputa se trasladó al Bajo Atrato con la intención de controlar una de las zonas estratégicas más importantes de Colombia, que conecta la costa del Atlántico con el océano Pacífico, Panamá y el interior del país. A pesar de que la guerrilla hace presencia en esta zona desde los años 1980 (Rojas 2004), y ejerce control sobre el territorio y en especial sobre la comercialización de madera, fue con la incursión de las Autodefensas Unidas de Córdoba y Urabá — a mediados de los años 1990que se agudizó el conflicto por los enfrentamientos entre los paramilitares, el Ejército Nacional y la guerrilla (GMH 2013; Rojas 2004).

En este contexto ocurrió el desplazamiento masivo en el Bajo Atrato, a causa de las operaciones Génesis y Cacarica, lideradas por la XVII Brigada del Ejército Nacional y las Autodefensas Unidas de Colombia (AUC). Estas operaciones militares involucraron hostigamientos, bombardeos aéreos y asesinatos de la población civil en distintos consejos comunitarios de la zona. Según las entrevistas realizadas en la comunidad de Bijao, un grupo paramilitar llegó advirtiendo que estaban buscando guerrilleros y que les daban un plazo de tres días a los miembros de la comunidad para que desocuparan el territorio. Sin embargo, debido a los estragos del hostigamiento — que implicó disparos a la población civil—, muchas personas salieron de las comunidades el mismo día; algunos huyeron hacia Panamá mientras que otros fueron hacia el Atrato para llegar a Turbo.

Quienes se dirigieron a Panamá llegaron en un primer momento a las comunidades indígenas ubicadas en la frontera con Colombia, después fueron acogidos por el Gobierno panameño, para luego ser repatriados y, de manera concertada, reubicados en Bahía Solano (Chocó). Por otro lado, quienes salieron hacia el río Atrato se refugiaron en Turbo y Mutatá (Antioquia), en condiciones de hacinamiento que generaron diversos problemas de salud pública. Allí estuvieron durante los dos años que tomó la construcción de dos albergues ubicados en el municipio de Turbo. Sobre este asunto, la Corte IDH (2013) responsabilizó al Estado colombiano por el desplazamiento forzado de las comunidades del Consejo Comunitario de la Cuenca del Río Cacarica, al concluir que se produjeron actos de colaboración entre la fuerza pública y las unidades paramilitares en el desarrollo de las operaciones Génesis y Cacarica. Además, esta Corte comprobó las relaciones entre las empresas madereras (que por esa época explotaban recursos forestales en la región) y los grupos paramilitares, en particular, el caso de la empresa Maderas del Darién que pagaba al Bloque Élmer Cárdenas para darles viabilidad a sus actividades económicas. Según la Comisión Intereclesial de Justicia y Paz (s. f.), los hechos de violencia ocurridos desde el desplazamiento forzado aseguraron la extracción de madera a gran escala, la destrucción de los bosques para la implementación de la ganadería y el establecimiento de monocultivos de 
palma aceitera, plátano y yuca, así como la estrategia económica paramilitar que incluyó la siembra de cultivos ilícitos en el Bajo Atrato.

No son pocas las investigaciones que han permitido asociar la planeación de megaproyectos de "desarrollo" económico con el desplazamiento forzado de poblaciones humanas. Rosero (2002), por ejemplo, destaca que las poblaciones afrodescendientes en el país son desplazadas de sus territorios para poner en marcha proyectos mineros, viales y agroindustriales, entre otros. Así mismo, Escobar (2004) analiza cómo esas iniciativas económicas, que pertenecen al despliegue de un paradigma de desarrollo moderno y capitalista, se anclan en una visión de desarrollo occidental que promueve el desplazamiento de las comunidades en función de los proyectos económicos y en desmedro de la biodiversidad de los territorios. Para el caso del Cacarica, las relaciones evidenciadas por la Corte IDH (2013) entre grupos armados y grupos empresariales sobre la explotación de madera y el cultivo de palma de aceite, para "desarrollar" la región y el país, permiten inferir que el desplazamiento forzado de las comunidades es una estrategia recurrente para garantizar el "desarrollo" económico capitalista, que también atenta contra las formas de relacionarse con el territorio que los grupos humanos han construido y que históricamente les permitieron la reproducción de su vida, cultura y saberes.

En el entendido de que el territorio es base y fundamento de la identidad (Hoffmann 2002) de las comunidades negras, en tanto "espacio fundamental multidimensional en el que se crean y recrean las condiciones de sobrevivencia de los grupos étnicos y los valores y prácticas culturales, sociales y económicos que les son propios” (Grueso, Rosero y Escobar 1997, 60) el desplazamiento no solo representa una afrenta contra las comunidades y la naturaleza, sino también contra las prácticas, saberes y sentidos que la gente ha construido entre sí y con el territorio. En esa medida, es una herramienta moderna/colonial al servicio del Estado y grupos empresariales de gran poder para promover la homogeneización de saberes, vulnerar el poder de las comunidades de decidir su rumbo de vida y de gestionar su propio devenir, privilegiando así el desarrollo económico sobre la dignidad y la vida.

\section{Fortalecimiento organizativo}

El fortalecimiento organizativo se entiende aquí como el proceso —aún inacabado- que empezaron a desarrollar las familias del Cacarica luego del 
desplazamiento forzado, y que incluye diversas estrategias: el refuerzo de sus capacidades internas, la autogestión de mejores condiciones de vida, la apropiación de las herramientas conceptuales de los derechos humanos y étnico-territoriales, la creación de organizaciones de base, entre otras. Estas acciones territoriales se elaboran a partir de la construcción de alianzas intersectoriales, globales y locales que ponen en conversación intereses, saberes y prácticas de los modos de vida de las comunidades con las lógicas y herramientas jurídicas de orden nacional e internacional, configurando así ejercicios de gobernanza ${ }^{4}$ y resistencia cultural para defender la vida, el territorio y la posibilidad de "ser" con él.

El proceso de fortalecimiento organizativo se inició con el desplazamiento mismo. Cuando las familias llegaron a los sitios de refugio en Panamá y Colombia, designaron voceros y representantes para que interactuaran con las diferentes instituciones, en especial, con el Estado colombiano. Entre las organizaciones que brindaron atención a la emergencia se encuentran la Comisión Intereclesial de Justicia y Paz, Peace Brigade International Colombia (PBI Colombia) ${ }^{5}$, la Oficina del Alto Comisionado de las Naciones Unidas para los Refugiados (Acnur), la Cruz Roja Internacional, el Centro de Investigación y Educación Popular (Cinep), Opción Legal y el Ministerio del Interior. Con su apoyo, las familias del Cacarica lideran un proceso de organización interna que puede ser concebido también como un proceso de resistencia frente a las condiciones de vida y las lógicas impuestas por el desplazamiento, que implican la desterritorialización, la consolidación de relaciones históricamente inequitativas y la prolongación de diferentes tipos de violencias sobre las comunidades negras.

Bajo el principio de unión, las vocerías establecidas entre las familias desplazadas les permitieron "hablar un solo lenguaje”” y viabilizar la interlocución con las instituciones, es decir, unificar intereses y discursos ante los actores externos y, en particular, el Estado. Los liderazgos que se mantienen en la actualidad, no solo en las juntas de gobierno del CCCRC, fueron designados principalmente

4 La gobernanza es entendida aquí como un ejercicio participativo que integra diversos actores, saberes y recursos para construir un proyecto de vida colectivo, que en el caso del Cacarica está fundamentado en el logro de la vida digna y la reconstrucción del territorio. Se convierte así en una capacidad para la autonomía, la autodeterminación y el gobierno propio, es decir, en una capacidad para definir el propio futuro y gestionarlo.

$5 \quad$ PBI es una ONG defensora de los derechos humanos que promueve el acompañamiento de liderazgos y la construcción de paz y justicia.

6 Expresión usada por uno de los miembros de la comunidad de Bijao, para exponer la necesidad de unir fuerzas entre las familias desplazadas y consolidar la organización, frente a la percepción colectiva de un Estado que los quería dispersos. 
en reconocimiento de las autoridades familiares y comunitarias ${ }^{7}$ que existían antes del desplazamiento y tuvieron entre sus funciones integrar a las familias de las veintitrés comunidades de la cuenca en un mismo proceso. Esas formas de representación comunitaria se mantienen en el territorio y su capacidad de toma de decisiones está mediada por las observaciones, críticas y disposiciones de las comunidades. En el trabajo de campo constaté que los voceros designados no toman decisiones importantes sin consultar previamente con el resto de la comunidad; ese accionar les permite a los voceros, independientemente de si pertenecen o no a las juntas de gobierno, contar con legitimidad social debido a la valoración que se hace de su experiencia y su compromiso comunitario.

Luego de designar vocerías y liderazgos en las comunidades, el proceso organizativo gestado con más fuerza se desarrolló en Turbo, tal vez porque allí se encontraba la mayoría de la población desplazada y había más presencia de las organizaciones humanitarias y organizaciones no gubernamentales (ONG). Según los testimonios que recopilé en la comunidad de Bijao, en Turbo las familias crearon comités organizativos para mejorar las condiciones de vida en el refugio y empezar proyectos de formación en diferentes temas. Los comités permitieron ordenar asuntos básicos, como el uso de los baños comunitarios, las zonas de lavado y la disposición de basuras. También se crearon comités para abordar asuntos más complejos, como el trabajo, matriarcas y patriarcas, familiares de víctimas de asesinatos, cultura, mujeres en resistencia, salud, infancia, jóvenes, educación, bodega y proyectos productivos, y para las negociaciones con el Estado se conformó el comité de diálogo.

En estos grupos, que tenían representación de las diferentes comunidades desplazadas, se desarrollaron jornadas de capacitación y de construcción de propuestas o planes para retornar al territorio. A partir de estos se crearon organizaciones de base, entre las que se destaca la Asociación de Comunidades de Autodeterminación, Vida y Dignidad: Por la Defensa de la Vida y el Territorio (Cavida), que es considerada la gran escuela del proceso organizativo en el Bajo Atrato y fue el escenario de aprendizaje de la mayoría de los líderes reconocidos en el Cacarica (Escorcia 2016). En el marco de las acciones desarrolladas por Cavida, con acompañamiento de algunas organizaciones internacionales, se fortalecieron los procesos de liderazgo comunitario, en particular, se generó un profundo aprendizaje sobre derechos humanos, el derecho internacional

7 Por ejemplo, las juntas de acción comunal que existían antes del desplazamiento y que pierden vigencia jurídica con la construcción del consejo comunitario y otras formas de liderazgo con legitimidad social no definidas por ninguna normativa. 
humanitario y la normatividad nacional e internacional que ampara los derechos étnico-territoriales y colectivos de las comunidades negras.

El proceso de formación apoyado por la Comisión Intereclesial de Justicia y Paz y PBI Colombia, con los comités organizativos y Cavida, les permitió a las comunidades conocer sus derechos y reflexionar sobre las condiciones de su existencia:

se aprendieron muchas cosas fundamentales, donde la gente aprendió a reclamar sus derechos, a darse cuenta que como persona tenemos derechos y tenemos deberes. Tenemos valores que uno nace pero uno a través del tiempo tiene que pues ir adquiriéndolos y los derechos fundamentales que tenemos todas las personas, porque uno vive y no sabe que tú los tienes y que hay unos derechos que tienes que aprender a reclamarlos. Entonces la gente aprendió muchas, muchas cosas aprendió la gente. (Entrevista con líder de la comunidad de Bijao, 4 de septiembre del 2018)

Es así como Cavida, además de considerarse una organización que lucha por la vida y el territorio, también es percibida por muchos de los pobladores como una escuela de formación política, que fortaleció los liderazgos y ha sido clave para la permanencia de las comunidades en el Cacarica. La formación política se constituyó en un elemento clave para la gobernanza en el territorio, aun sin estar en él, pues posibilita la gestión ante el Estado de condiciones que las comunidades consideran básicas para el retorno, de tal manera que los aprendizajes sobre los derechos humanos y territoriales se convierten en una guía para visionar y planear el territorio. Parte de ese ejercicio tuvo como insumo clave la creación de un pliego de peticiones que fue negociado con el Gobierno nacional, como requisito para retornar. El documento, que se construyó con el asocio de las comunidades de las cuencas de Domingodó, Curvaradó y Vigía de Curvaradó, ubicadas también en el Bajo Atrato, se basó en la descripción de cinco puntos (Desplazados de la cuenca del Cacarica et al. 1998) que, en esencia, demandan el establecimiento de garantías territoriales para volver al Cacarica:

1. Construcción de tres asentamientos donde se respete la vida y se exija el cumplimiento de los derechos humanos y la aplicación del derecho internacional humanitario.

2. Titulación de tierras colectivas en uso de los derechos territoriales concebidos por la Ley $70^{8}$ y en coherencia con la creación del Consejo Comunitario de la Cuenca del Río Cacarica. de 1991. Reconoce a las comunidades negras como grupo étnico y legitima la titulación de la propiedad colectiva en la cuenca del Pacífico, en razón del uso ancestral que han realizado las comunidades negras en dichos territorios. Con base en esta ley y el Decreto Reglamentario 1745 de 1995, se define al consejo comunitario como persona jurídica y máximo órgano de administración interna, liderado por una junta elegida en asamblea general — constituida esta 
3. Protección, en reconocimiento de su condición de objetivo militar, que implica la generación de acuerdos humanitarios, la observación de los acuerdos, la creación de una comisión de verificación y la presencia de organismos de control del Estado y autoridades de promoción y la Defensoría del Pueblo.

4. Desarrollo Comunitario que involucra el restablecimiento de las condiciones de vida de las familias en el territorio, la consolidación de equidad y justicia en el mismo, el desarrollo de sus iniciativas económicas, políticas y sociales.

5. Reparación moral que se materialice en el reconocimiento de los hechos de violencia, identificación de los responsables, conformación de una comisión interinstitucional de investigación de los hechos sucedidos, construcción de monumentos en memoria de los asesinados, desaparecidos y demás víctimas, publicación de un libro que consigne la memoria del desplazamiento, la elaboración de una película donde evidencie la memoria del pasado, el presente y el futuro de la población, y la elaboración de una serie radial de la memoria colectiva. (Desplazados de la cuenca del Cacarica et al. 1998)

Con la aceptación total del pliego de peticiones por parte del Estado, el consejo comunitario logró obtener el 26 de abril de 1999 la titulación colectiva ${ }^{9}$ de 103.024 hectáreas. Posteriormente, a solicitud de Cavida, se construyeron en el territorio dos asentamientos: Nueva Esperanza en Dios y Nueva Vida. Sin embargo, sobre las peticiones referidas a la protección y el desarrollo comunitario existen pocas acciones realizadas. Frente a este asunto, miembros del consejo comunitario expresan que el Estado no ha cumplido con los acuerdos surgidos del pliego de peticiones, que fueron una condición para retornar al territorio. En relación con la reparación económica, algunas personas manifiestan no sentirse reparadas ni reivindicadas con las formas definidas por el Estado, pues sus intereses de reparación, más que pagos o indemnizaciones, están dados por el deseo de recuperar las condiciones de vida que tenían antes del desplazamiento forzado, además del reconocimiento de los hechos ocurridos, el esclarecimiento de

por todos los miembros del territorio colectivo-, que ejerce autoridad territorial a partir de reglamentos internos para el gobierno y convivencia dentro del territorio.

9 Bajo la Resolución 0841 de 1999, el Instituto Colombiano de la Reforma Agraria (Incora) tituló las tierras colectivas del consejo comunitario. Vale la pena aclarar que el proceso de titulación requiere previamente -entre otros procedimientos- la creación del consejo comunitario como persona jurídica, la elección de una representación legal, la creación de la junta del consejo y la aprobación de la asamblea general. Esto para aclarar que la constitución del consejo per se no implica la adjudicación del título colectivo, a pesar de haberse constituido en reconocimiento de uso ancestral del territorio. 
los actores responsables y las causas de los eventos de violencia, tal como se narra en el siguiente fragmento de entrevista:

Porque anteriormente la comunidad vivía muy unida, había una buena hermandad, una buena convivencia, tanto dentro de la comunidad como con otras comunidades particulares, teníamos un roce de compartidos. Entonces la gente compartía mucho, jugaba, se hacían muchos eventos recreativos donde participaba todo el sector de la cuenca, se hacía fiesta de la escuela, es decir, se hacían diferentes eventos donde la gente mantenía esa interacción. (Entrevista con líder de la comunidad de Bijao, 1. $^{\circ}$ de septiembre del 2018)

Así, se puede reconocer que las medidas de reparación del Estado poco responden a los intereses de las comunidades y distan de lo acordado. Además, el concepto mismo de reparación difiere de las propias concepciones de la comunidad, que ha manifestado su incredulidad de que sea posible recuperar la forma de vida que tenía antes del desplazamiento, no solo por los bienes materiales destruidos sino por las redes sociales y familiares que se fracturaron, los proyectos comunitarios que se perdieron, las personas y familias que nunca regresaron al territorio, además de las muertes, las violencias soportadas y el trauma que esas acciones les han dejado.

La inconformidad manifiesta de las familias permite entender por qué, a pesar del uso de los conceptos y las herramientas normativas y el acompañamiento de organizaciones externas, los intereses y significados comunitarios en torno a la reparación desbordan el marco jurídico. Vista desde ahí, la reparación consolida como elemento principal las condiciones materiales de vida de las comunidades pero no integra las experiencias y saberes propios de estas, que se ponen en discusión por sus reclamos por el tejido y las relaciones sociales que configuran el territorio. Es decir, por sus modos de vida, "aún más cuando el discurso de los derechos humanos está desconociendo el carácter colectivo del sujeto, del Ser negro-negra dentro de la resistencia/re-existencia y el proceso organizativo" (Grueso 2006, 156).

\section{Creación del consejo comunitario, la junta mayor y las juntas locales}

Es importante mencionar que, antes del año 2000, las comunidades hoy conocidas como parte del CCCRC no estaban constituidas como tal, lo que implicaba que, a 
pesar de que existieran centros poblados o comunidades, estos no eran titulares de la tierra de manera colectiva y su ocupación estaba definida por la tenencia de algunos títulos privados y por ocupaciones familiares en baldíos del Estado.

Digamos, eso fue iniciativa de la población, sino que inicialmente la idea era presentar las veintitrés hojas de vida, porque la titulación se estaba buscando individual, por comunidad, pero fue rechazada por el Estado, ese poco de solicitudes, de títulos. ¿Qué fue lo que sucedió? Se miró [...] que la titulación así por comunidad de pronto mucho terreno quedaba suelto. Entonces rápidamente la gente miró una titulación colectiva donde abarcara todo el territorio. (Entrevista con líder de la comunidad de Bijao, $1 .^{\circ}$ de septiembre del 2018)

Como se puede interpretar a partir de la narración anterior, la titulación responde a una estrategia para asegurar la legítima posesión de la tierra que por años las familias negras y mestizas habían ocupado. Esto implicó, entre otras cosas, la concertación de la unión territorial de las veintitrés comunidades bajo la figura de territorio colectivo, que define para todos por igual regulaciones sobre el aprovechamiento de los recursos naturales, en aras del cumplimiento de la función ecológica y social establecida por la Ley 70. Esa condición generó importantes tensiones entre las familias negras y mestizas, pues, tal como lo describe Ruiz-Serna (2011), para el caso de otras comunidades en el Bajo Atrato implicó la aceptación por parte de las familias negras de la permanencia y aprovechamiento de los terrenos que desde hacía décadas las familias mestizas habían realizado en el Cacarica. Asumirse como parte del consejo comunitario implicó para estas familias subordinarse a las regulaciones que la ley y que el mismo proceso organizativo demandan, por ejemplo, sobre la resolución de conflictos, el aprovechamiento del suelo, la extracción de madera y otras actividades productivas que son reguladas colectivamente en el reglamento interno. Para el caso del Cacarica, uno de los líderes comunitarios lo expone de la siguiente manera:

La verdad es que nosotros, a pesar de que la ley nos dice una cosa, cuando se crea la "Ley Negra", se le dice así a la Ley 70, entonces ella lo dice muy claro: estas son comunidades negras, territorio negro, entonces en ese tiempo a los mestizos teníamos que sanearles y que se fueran del territorio, entonces es allí donde nosotros no entramos, porque siempre hemos vivido con ellos... (Entrevista con líder de la comunidad de Bijao, 2 de septiembre del 2018)

Esa decisión evidencia cómo las diferencias culturales y sociales de ambos grupos - que se ponen en tensión a causa de las políticas multiculturalistas que les reconocen derechos especiales a las comunidades indígenas y afrodescendientes- terminan viéndose reducidas, en el marco de la acción colectiva, para 
garantizar el derecho de las familias a desarrollar su vida en el Cacarica. Además, impone por encima de las definiciones de la ley de comunidades negras las relaciones sociales que la gente había construido históricamente, promoviendo así la acción política conjunta y la convivencia social. La condición de “unidad”, que puede parecer una estrategia estrictamente administrativa, implicó para las distintas comunidades definirse no solo como vecinos sino como parte de un mismo territorio, que además atribuye a las personas la categoría de miembros de un consejo comunitario con autoridad étnico-territorial propia.

Asociado a ello, a partir del trabajo de campo logré identificar que, a pesar de que las comunidades negras se autorreconocían como tales y habían sido conscientes de su etnicidad y de las diferencias culturales con otros grupos humanos, no sabían que esa condición había sido reconocida por el Estado con una categoría de ciudadanía especial y que, desde 1993 con la Ley 70, se les reconoce el derecho colectivo de uso y aprovechamiento tradicional de tierras baldías en la cuenca del Pacífico. La apropiación de esos derechos es un eje central en el proceso de titulación del consejo comunitario, porque genera para las comunidades desplazadas un tipo de representación política y de gobernabilidad diferente a la que tenían antes del desplazamiento; es decir, una reflexión de ellas como sujeto político y de derechos a partir de la resignificación de su identidad étnica.

Es que en ese momento que se da el desplazamiento, hay un desconocimiento de cuáles son tus derechos, entonces, cuando ya te hacen esto que te desplazan, te maltratan, ya tú empiezas a tomar conciencia y empiezan a llegar unas personas que brindan un acompañamiento y unas asesorías que de una u otra manera le sirven a la población y uno dice “¡wow, yo no conocía esto!”. Y entonces ya empieza un proceso de aprendizaje, hasta el punto de que nosotros éramos de comunidades negras pero nunca nos habíamos trazado metas, a decir: "bueno, tenemos que organizar un plan de desarrollo, tenemos que organizar una carta de navegación”. Y ya tú hoy llegas a las comunidades y te sientas con cualquier persona y te muestra el reglamento que está basado en esto y en esto. Yo pienso que hay un avance, hay un cambio positivo de la población. (Entrevista con líder de la comunidad de Bijao, 3 de septiembre del 2018)

Esos aprendizajes generaron nuevas posibilidades de reivindicación de sus derechos a partir de repensar la identidad como categoría política. En otros términos, pensar la negritud o la afrodescendencia en el marco de luchas políticas históricas en las que las comunidades negras han ocupado roles subalternos $y$, en este caso concreto, legitimar el proceso organizativo de las comunidades bajo la categoría de consejo comunitario y autoridad étnico-territorial. En el fondo de esa elaboración se revela la habilidad de las comunidades para apropiarse 
de las herramientas jurídicas de las políticas multiculturales construidas en la lógica de poder en la que han sido violentadas; es decir, apropiarse de las herramientas de un Estado que planificó su territorio sin tenerlos en cuenta, les arrebató el control sobre este y los desplazó.

Ahora bien, esa investidura de autoridad es la que permite que se gestione - también durante el tiempo de desplazamiento- la titulación colectiva de las 103.024 hectáreas adjudicadas al consejo según la Resolución 00841 de 1999 del Instituto Colombiano de la Reforma Agraria (Incora), hoy llamado Agencia Nacional de Tierras (ANT). La decisión de unir a las diferentes comunidades para gestionar el consejo comunitario y la titulación del territorio colectivo implica la configuración de un nuevo elemento sobre su identidad, en el que, además de haberse asumido como colectivos y sujetos de derechos, ahora se reconocen como parte de una misma unidad administrativa que comparte una figura de autoridad étnico-territorial. Antes de salir de sus territorios se reconocían entre sí como familias y comunidades, pero regresaron investidos con una categoría étnico-territorial (consejo comunitario) que instaura un sentido de unidad colectiva entre las veintitrés comunidades y una herramienta jurídica clave (título de propiedad colectivo) para defender las tierras que consideran propias.

Cuando nosotros regresamos sí estaba el título colectivo, cuando la gente salió esto no eran tierras tituladas, eran tierras que el Estado llamaban baldíos, sino que cada comunidad sabía que llegaba aquí y que ese terreno de ahí de donde colindaba hacia acá le pertenecía, y que en ese terreno cada comunidad, cada familia tenía su pedacito de tierra, pero eran tierras baldías, no estaban reconocidas por el Estado como tal. Entonces, cuando la gente salió de desplazado, uno de los primeros pasos fue la titulación, cuando la gente regreso aquí, la gente venía con título en mano. (Entrevista con líder de la comunidad de Bijao, $1 .^{\circ}$ de septiembre del 2018)

Sí, nosotros estamos seguros de que el título es una herramienta si la sabemos utilizar, en defensa del territorio [...] que es lo que nosotros estamos mirando. (Entrevista con líder de la comunidad de Bijao, 3 de septiembre del 2018)

Para dar cumplimiento a las funciones de autoridad étnico-territorial se consolidó una estructura de gobierno compuesta por una junta directiva, una representación legal y la asamblea comunitaria, que es el espacio de decisión de mayor importancia y está constituido por todos los miembros adscritos al consejo. Para el caso particular del Cacarica - y de otros consejos en el departamento del Chocó-, además de las figuras mencionadas, existieron consejos y juntas locales que eran equiparados en una escala local a las figuras de consejo 
comunitario y junta directiva que también funcionan en la escala mayor. Si bien la junta directiva es la máxima figura de representación y autoridad en el territorio, existían traslapes en las funciones de los consejos y juntas locales en términos de la representación de los miembros de cada comunidad. Estos consejos no eran personas jurídicas ni tenían titulaciones parciales de tierra, pero cumplían un rol de gran importancia en la organización comunitaria, la gestión de recursos, la participación política dentro del consejo comunitario, la interlocución con organizaciones externas, grupos armados y hasta con la misma junta directiva del consejo comunitario mayor, entre otros. La creación de los consejos locales evidenciaba la necesidad de cada comunidad de consolidar estructuras de poder que les brindaran cierta autonomía en el marco de la unidad que define al consejo comunitario. Pese a lo anterior, con la creación del reglamento interno en el año 2016, las comunidades reflexionan sobre el hecho de que la titularidad de la tierra esté asignada al CCCRC y, aunque se admite la existencia de las comunidades, no hay un reconocimiento jurídico de los consejos locales; es así como acuerdan eliminar la figura del consejo local y regular, las competencias de las juntas locales y la junta del consejo. Sin desmedro de lo anterior, en el trabajo de campo y en el acompañamiento a los procesos organizativos del consejo comunitario - entre ellos, la creación de un reglamento interno-, noté la existencia de múltiples tensiones entre la junta del consejo comunitario y las juntas locales de algunas comunidades por los intereses de autonomía de estas, que para la junta del consejo resultan contradictorias con sus funciones de representación y autoridad. Esto genera disputas de poder por la toma de decisiones en el territorio.

Teniendo en cuenta las estrategias nombradas y las interpretaciones de los líderes en la comunidad de Bijao identificadas en el trabajo de campo, se puede argumentar que el proceso de formación política desarrollado por las familias del consejo en asocio con la organización Cavida y las ONG que las atendieron desde el momento del desplazamiento; la creación del consejo comunitario; la titulación colectiva de la tierra; la construcción de instrumentos de gobierno propio, como el reglamento interno, y la resignificación de la identidad y el ejercicio del ser comunidad negra han sido acciones consideradas por los habitantes del Cacarica como estrategias para defender y crear el territorio y la vida comunitaria, que le dieron legitimidad a la posesión de las tierras que por décadas venían ocupando. Además, invistió el proceso organizativo con una figura de autoridad que dispone de mayores herramientas y recursos para establecer una interlocución con el Estado, las empresas privadas y los grupos armados al margen de la ley, promoviendo la preexistencia de las comunidades en el Cacarica, a pesar de las consecuencias del desplazamiento, como se puede interpretar a partir del siguiente testimonio: 
Sí, la lucha que se ha venido dando aquí ha sido de tratar de formar la comunidad, hemos estado bastante organizados, en cuanto a talleres sobre la Ley 70 y conocer nuestros derechos, cómo debemos de respaldarnos o dónde tenemos que quejarnos, y cómo activar las alertas tempranas en caso cualquier emergencia. (Entrevista con líder de la comunidad de Bijao, 4 de septiembre del 2018)

Como lo deja entrever el relato del líder comunitario, la formación política de las comunidades ha sido y sigue siendo una apuesta necesaria para viabilizar la vida en el Cacarica. En este punto, las acciones de fortalecimiento organizativo, las alianzas y el trabajo colectivo entre las comunidades permiten establecer una construcción conjunta de identidad y territorio que se asocia directamente con: 1) la formación de sujetos políticos a partir de la reivindicación de la etnicidad y el reconocimiento de sí mismos como sujetos de derechos; y 2) la construcción de nuevas representaciones sobre el territorio que, además de seguir siendo el lugar donde las comunidades reclaman el uso tradicional y desarrollan la vida, es el sitio que por derecho les pertenece y sobre el cual son autoridad, en coherencia con las nuevas reflexiones sobre la identidad. Esa relación hace posible el territorio como espacio fundamental multidimensional (Grueso, Rosero y Escobar 1997), donde se construyen las relaciones sociales; donde se caza, se pesca, se cría, se aprende; y, en general, donde es posible que la vida de las familias desplazadas del Cacarica se resignifique a partir de la acción política de las comunidades y sus ejercicios de gobernanza, consolidando resistencias y reexistencias, en el marco de luchas políticas que en el fondo son ontológicas en tanto abogan por ser con y en el Cacarica:

la verdad es que, cuando hubo ese desplazamiento, la gente también, las comunidades en cierto sentido se fortalecieron mucho organizativamente, entonces, cuando ya la gente dentra como ese rol organizativo, entonces es cuando ya la gente empieza a tener esa lucha, esa pelea por su tierra, su territorio, entonces ya es cuando nos decidimos venir al territorio, que no podíamos permitir que lo tomara otro, entonces ya la gente empezó a abrir los ojos [...]. Pues en el momento que a uno le da ese ánimo, era la cuestión de que uno allá en el pueblo no tenía absolutamente nada, no tenía dónde vivir, pasaba mucha hambre, mucho trabajo, mientras uno acá tenía sus tierras [...]. Por eso fue por lo que se conformaron los consejos comunitarios, hemos también hecho nuestras propias leyes como lo son las cartas magnas ${ }^{10}$, los reglamentos internos y eso es lo que nos ayuda a proteger y convivir en este territorio [...] Pues el territorio lo hemos protegido de acuerdo con lo que quedó allí 
en el título colectivo, de acuerdo con lo que nos ampara la Constitución Política de Colombia, la Ley 70, nos hemos empapado un poco de eso y siempre es eso lo que nos ha ayudado a proteger el territorio. (Entrevista con líder de la comunidad de Bijao, 2 de septiembre del 2018)

Sin perder de vista que, además de los nuevos conocimientos y reflexiones, dichas acciones se sustentan en los significados del territorio:

Para mí significa todo porque desde el momento que me hicieron aquí, nací aquí, prácticamente me crie aquí, o sea, no hay cosa que desee más que estar aquí en mi comunidad y por eso es el motivo que uno se mete al cuento, llega al liderazgo para así tratar de defender su territorio lo más que se pueda. Es el sentir y por lo que uno vive muy en paz en sus tierras, donde uno nadie le va a decir: “venga, págueme el alquiler” o algo así. (Entrevista con líder de la comunidad de Bijao, 2 de septiembre del 2018)

\section{Gestión para el retorno y la ocupación del territorio: reconfiguración y resignificación de la vida y la territorialidad}

Es necesario señalar que, desde el momento en que fue desplazada, la gente estaba pensando en regresar, porque el Cacarica es su lugar de origen, donde la mayoría nació; donde se criaron; tuvieron sus hijos; crearon nuevas familias; aprendieron a cultivar, a cazar, a pescar; donde aprendieron a vivir y generaron las condiciones que consideraron necesarias para hacer posibles sus formas y proyectos de vida. Así, luego de negociar con el Estado el pliego de peticiones para el retorno, se conformó una comisión de exploración con la participación del Gobierno nacional, víctimas y ONG, que tuvo como objetivo conocer de primera mano el estado en el que se encontraba el territorio luego de más de tres años del desplazamiento. Con base en este ejercicio se inició el retorno en dos fases: en la primera regresaron 270 personas y en la segunda, 84. Estas dieron paso al regreso paulatino de alrededor de 600 personas al Cacarica (Corte IDH 2013).

En el proceso de retorno, una de las acciones más importantes fue la creación de dos zonas humanitarias conocidas como Nueva Vida y Nueva Esperanza en Dios, para proteger a las personas de los ataques de grupos armados. Estas figuras comunitarias se formaron a partir del reconocimiento del derecho internacional humanitario y permiten que las comunidades se declaren como actores 
neutros en escenarios de conflicto. Tal como lo muestra el siguiente fragmento de la entrevista con uno de los líderes de la junta del consejo comunitario, las zonas humanitarias representaron un espacio de seguridad para las familias:

Las zonas humanitarias las crearon en forma de protección. Esas personas que quedaron allí en esas zonas humanitarias son personas que son, por decirlo así, intocables, los que quedaron allí son personas que quedaron protegidas. (2 de septiembre del 2018)

La creación de estas zonas se configura en un elemento clave que consolida otras formas de concebir el territorio, es decir, de ordenarlo. Estos sitios, que fueron pensados como transitorios, se han mantenido en el tiempo y en la actualidad gozan de los mismos derechos y condiciones de participación de las veintitrés comunidades del Cacarica, con la particularidad de que están integradas por personas que antes del desplazamiento hacían parte de las veintitrés comunidades del territorio colectivo. Ahora bien, la planeación inicial realizada por los líderes y las organizaciones acompañantes estimaba que las familias permanecerían en las zonas humanitarias por tres años y luego se realizarían los retornos internos.

Entonces, retornamos en dos asentamientos, con una condición de que íbamos a retornar en medio de la guerra y que estábamos conscientes de que iba a seguir pasando cosas [...] entonces, ya retornados, dentro del marco del retorno, quedan unos acuerdos, unas zonas de cultivo, que una vez dadas las condiciones usted podía regresar, o sea, como un retorno interno pero quien tenía la responsabilidad: el Estado, ¡no cumple! (Entrevista con líder de la comunidad Bijao, 3 de septiembre del 2018)

La mayoría de las familias permaneció en las zonas humanitarias los dos primeros años y regresó de manera esporádica a sus territorios. El incumplimiento de los tiempos acordados de permanencia en estos sitios se debió - entre otras cosas - a que las familias llegaron a lugares que, a pesar de ser construidos por ellos mismos y de estar dentro del territorio colectivo adjudicado, no eran sus comunidades de origen (de las que fueron desplazadas), por lo que no podían contar con las tierras que tradicionalmente habían aprovechado para trabajar. Asociado a esto, la delimitación física que se hizo de la zona humanitaria restringía la movilidad y la tierra disponible no garantizaba suficiente espacio para que todas las familias pudieran cultivar como deseaban. Se generaron además inconformidades con el apoyo de Justicia y Paz, que establecía comunicación con el Gobierno nacional en representación de las comunidades desplazadas, en especial por el manejo de los recursos aportados por el Estado y la exigencia de 
normas de convivencia que habían sido pactadas internamente pero que luego hicieron sentir en una condición de encierro a las personas refugiadas en las zonas humanitarias.

Pero lo que no estuvimos de acuerdo de estar en esas zonas humanitarias fue porque debíamos estar en un solo sitio, y mientras tanto uno sufriendo ahí, y su comunidad acá, entonces fue por eso que decidimos salirnos algunos de esas zonas humanitarias. (Entrevista con líder de la comunidad de Bijao, 2 de septiembre del 2018)

Según algunas personas del consejo, existía una fuerte regulación de la comunicación de quienes estaban refugiados con personas que no se encontraran en las zonas humanitarias, con la intención de que el aislamiento impidiera el contacto con grupos armados. Algunas familias y hasta comunidades enteras, como la de Puente América, decidieron no vincularse a las zonas humanitarias por no estar de acuerdo con las medidas tomadas para salvaguardar la vida. Quienes sí permanecieron en las zonas humanitarias algún tiempo y luego decidieron regresar a sus comunidades lo hicieron sin ninguna protección institucional pero tomando medidas de seguridad. Esto implicó hacer avanzadas para reconstruir las comunidades mediante visitas semanales de pequeños grupos que empezaron a cultivar la tierra y desarrollaron jornadas de trabajo en las zonas cercanas que les permitieran regresar a las zonas humanitarias el mismo día. Posteriormente, empezaron a quedarse algunas noches en las comunidades hasta que se logró el retorno de algunas de las familias a sus lugares de origen, tal como lo narra uno de los líderes de la comunidad de Bijao:

ya la cosa estaba como tranquila, entonces dijimos: "estamos a dos horas, ¡vayamos cada uno por su cuenta!”. Vinimos quince familias acompañados por cinco que había acá. Había unas nueve casas que aguantaron toda la temporada del desplazamiento y no se cayeron, estaban habitables, entonces, nos repartimos ahí. (Entrevista con líder de la comunidad de Bijao, 3 de septiembre del 2018)

Retornar a las comunidades implicó una serie de esfuerzos de reconstrucción del territorio a través del uso y aprovechamiento de este, que son a la vez acciones de resistencia frente a los grupos armados y las lógicas que ocasionaron el desplazamiento. A pesar de haber acordado con el Estado la construcción de viviendas, puestos de salud, escuelas y otras instalaciones que permitieran el regreso a las comunidades, las familias de las zonas humanitarias y aquellas que desde mucho antes habían retornado al territorio por su cuenta tuvieron que reconstruir con esfuerzos propios los caseríos, adecuar caminos, despalizar ríos y generar las condiciones básicas para habitarlo: 
Nos tocó llegar fue a tirar hacha, sierra, a desmotar este pueblo porque acá simplemente cuando empezó a llegar la gente, simplemente había como cuatro a cinco casas, la casa de los profesores, dos casas de Marcial, la casa de un hermano mío, la casa de Vicente, un bailadero [...] y la casa del difunto Luis Lemus. Las otras casas se deterioraron, se cayeron, entonces esto se enmontó, fue amontado. Allí donde queda la cancha, nosotros esa cancha la reconstruimos fue covando de raíz y volver a rellenar porque esto aquí se nos dañó. (Entrevista con líder de la comunidad de Bijao, 4 de septiembre del 2018)

Según los relatos que recopilé en la comunidad de Bijao, este proceso implicó organizarse entre vecinos para construir y reparar las viviendas, e ir en convites $^{11}$ a cultivar y cazar, por temor a permanecer solos en el bosque y en los trabajaderos donde podrían encontrarse con algún actor armado. Durante la semana, grupos de alrededor de diez hombres se rotaban entre las parcelas familiares de cada uno para cultivar, adecuar terrenos, hacer mantenimiento de cultivos y cosechar. En la actualidad se puede evidenciar el uso y aprovechamiento casi total del territorio colectivo, aunque algunas de sus zonas siguen siendo vulneradas por la presencia transitoria de grupos armados, como lo ha denunciado la asociación Cavida en diferentes medios de comunicación ${ }^{12}$.

En el Cacarica, volver a usar la tierra, construir los caminos, adecuar los ríos, reproducirse, criar los hijos y, en general, establecer la vida en el lugar de origen es una forma de protegerse y de hacer y proteger el territorio que les pertenece. Es recrear formas de habitar en donde vida y territorio se construyen a la par:

el río, porque en ese lapso de desplazamiento que hubo, se sedimentó demasiado, los caminos se perdieron, el caserío se perdió, ¡todo, todo se perdió! Lo que tú tenías en tu casa, ya tú no lo conseguías, ya la casa estaba deteriorada, había que iniciar nuevamente con una vida, nuevamente. (Entrevista con líder de la comunidad de Bijao, 1. de septiembre del 2018)

Las familias han recuperado también la poliactividad que caracteriza las formas de aprovechamiento tradicional, sembrando la tierra, pescando, cazando $y$, desde hace algunos años, algunas de las comunidades de Bijao se han vinculado a la explotación de madera como la actividad primordial para la obtención de recursos económicos. Esas prácticas han sido esenciales para enfrentarse a las transformaciones que sufrió el territorio durante el desplazamiento, no solo por peacebrigades.org/es/pbi-colombia 
el abandono sino también por los usos ilegales de los recursos, en particular el aprovechamiento forestal de empresas como Maderas del Darién, contra la que se encontró evidencia del uso ilegal del bosque, aun cuando ya se había titulado el territorio colectivo y se había constituido el consejo comunitario (Corte IDH 2013).

En estas acciones que las comunidades consideraron esenciales para el retorno, lo que se gestiona no es solo la vida pensada en términos de las condiciones biológicas que establece la ciencia médica, sino la existencia/vida como referencia de la experiencia de ser, de estar, de hacer, de la capacidad de vivir según los deseos propios. En ese ejercicio, la gobernanza territorial se convierte en la posibilidad de gobernarse a sí mismos en contravía de los poderes impuestos por los actores armados, grupos económicos y el Estado que los desplazó.

Sí, porque tú sabes que si nosotros hoy en día, que nosotros somos campesinos, somos laboradores de la tierra, nosotros no lucháramos por la tierra, que esa es la que nos da fuente de vida, la fuente para poder sostener nuestras familias, entonces hay una lucha que es inmensa, porque es la única forma de nosotros poder sacar nuestras familias adelante. (Entrevista con miembro de la Junta del Consejo Comunitario y de la Comunidad de Bijao. Hombre de 55 años, septiembre del 2018)

Esos significados, además, ponen de relieve concepciones sobre el proyecto de vida comunitario que presuponen la coexistencia necesaria entre comunidad y territorio, de tal manera que el territorio es la fuente de vida de las comunidades y parte integral de su identidad.

Una comunidad sin tierra no es comunidad y la tierra sin comunidad tampoco es tierra, entonces es una cosa que está entrelazada [...]. Cuando yo pienso en un territorio, pienso en los tiempos atrás, que por eso estamos aquí. Porque nuestro territorio a nosotros nos sirve acá pa muchas cosas. En cuanto a las familias, los hijos los levantamos en el territorio. Nos levantaron a nosotros en el territorio, y levantamos nuestros hijos en el territorio, entonces, para nosotros estar acá en el territorio es algo importante y valioso, porque nosotros siempre desde los ancestros hemos vivido del territorio, la gente acá siempre ha vivido pendiente de su territorio porque esa ha sido su forma de vida de todo ser humano acá en el campo... (Relatoría taller realizado con mujeres de la comunidad de Bijao sobre salud, territorio y vida, 19 de septiembre del 2018)

A partir de las reflexiones anteriores, se puede entender que estar, vivir, ocupar y usar el territorio es una manera de defenderlo y reconstruirlo, en asocio con saberes y significados que emergen a partir de la acción colectiva y los procesos de liderazgo comunitario, pero también de las experiencias propias y la necesidad sentida de desarrollar la vida en el Cacarica, por ser negros, por ser 
campesinos, por considerar esos espacios la fuente de su vida. De esa manera, tanto la identidad como el territorio se reconfiguran uno al otro, en función de viabilizar el proyecto de vida comunitario.

\section{Consideraciones finales}

Las formas de proteger y construir la vida y el territorio en el Cacarica implican la revalorización de lo propio y la apropiación de lo externo en la construcción de territorialidades, figuras de autoridad y reflexiones alrededor de la identidad como comunidad negra y sujetos de derechos diferenciados. En el Cacarica se puede reconocer la existencia de un sentido de vida digna en referencia a "las oportunidades” que el territorio puede brindarles. En los discursos de los miembros del consejo comunitario se hace evidente el compromiso de protección del territorio y sus vidas, lo que ha generado que el proceso organizativo se haya mantenido y fortalecido en el tiempo desde el momento del desplazamiento.

A la luz de la experiencia documentada, se evidencia que las comunidades del Cacarica emprendieron un ejercicio de liderazgo que les permite acceder y ejercer el poder, entendido como la capacidad de tomar decisiones sobre el territorio y sobre sí mismos (gobernanza), que fue vulnerada por los actores violentos. El ejercicio de ese poder ha contribuido a desvirtuar los órdenes de subordinación a los que han sido sometidas históricamente y que se reflejaron en la lógica del desplazamiento forzado, en beneficio de la posesión y control del territorio por parte de terceros que imponen otras maneras de entender el territorio y el "desarrollo" de las comunidades. En la acción colectiva de estas se reconoce una gran capacidad de hacerles frente a las estrategias violentas que se les han impuesto en razón del desarrollo, pero también de "ser" según sus propios intereses y visiones del mundo, como sujetos políticos. Así, las acciones de las comunidades del Cacarica no son solo la posibilidad reivindicativa de otros mundos posibles -en el marco de la consolidación de un pluriverso, como lo nombra Escobar (2015)-, sino que también son una respuesta contrahegemónica a lógicas asociadas a las visiones modernas/coloniales del desarrollo, para las cuales las comunidades, sus modos de vida e intereses resultan ser incoherentes e incompatibles.

Es necesario entonces contribuir desde diferentes escenarios a la consolidación de estas apuestas, atendiendo a los reclamos y llamados de las comunidades, apoyando sus luchas y resistencias por la vida digna. En ese marco, la responsabilidad del Estado es clave y debe reestructurarse para que este país 
realmente pueda ser pluriétnico y multicultural, como se reconoce constitucionalmente. Ello implica que haya condiciones para la diversidad en el sentido más amplio de la palabra (ser, saber y poder), así como para las distintas formas de concebir el desarrollo.

\section{Referencias}

Avella González, Edgar. 2016. "Desplazamiento y subjetivación. El caso de los desplazados de la cuenca del Bajo Atrato”. Tesis doctoral, Universidad Pedagógica Nacional, Bogotá.

Castro-Gómez, Santiago y Ramón Grosfoguel, eds. 2007. El giro decolonial: reflexiones para una diversidad epistémica más allá del capitalismo global. Bogotá: Siglo del Hombre Editores; Universidad Central.

Comisión Intereclesial de Justicia y Paz. s. f. "Las zonas de biodiversidad en el Bajo Atrato por la defensa de la vida en el territorio”. Consultado el 30 de noviembre del 2019. http:// jyp.megadatesystem.com/IMG/pdf/zonas_de_biodiversidad_en_el_bajo_atrato.pdf

Congreso de Colombia. 1993. Ley 70 del 27 de agosto, "Por la cual se desarrolla el artículo 55 transitorio de la Constitución”.

Corte IDH (Corte Interamericana de Derechos Humanos). 2013. "Caso de las comunidades afrodescendientes desplazadas de la cuenca del río Cacarica (Operación Génesis) versus Colombia”. http://www.corteidh.or.cr/docs/casos/articulos/seriec_270_esp.pdf

De Sousa Santos, Boaventura. 2010. Descolonizar el saber, reiventar el poder. Montevideo: Ediciones Trilce; Universidad de la República.

Desplazados de la cuenca del Cacarica, familias de Domingodó, Curvaradó y Vigía de Curvaradó asentadas temporalmente en Turbo y Bocas del Atrato. 1998. "Pliego de propuesta: de retorno digno de las comunidades desplazadas de la cuenca del Cacarica y familias de Domingodó, Vigia de Curvaradó y Curvaradó concentradas en Turbo y Bocas del Atrato al Gobierno nacional”. Nova et Vetera 30: 4-17. https://doi.org/10.1145/2505515.2507827

Escobar, Arturo. 2004. "Desplazamientos, desarrollo y modernidad en el Pacífico colombiano”. En Conflicto e (in)visibilidad. Retos en los estudios de la gente negra en Colombia, editado por Eduardo Restrepo y Axel Rojas, 53-72. Popayán: Universidad del Cauca.

-. 2015. “Territorios de diferencia: la ontología política de los 'derechos al territorio””. Cuadernos de Antropología Social 41: 25-38. https://doi.org/10.34096/cas.i41.1594

Escorcia, Nicolás. 2016. "Acción colectiva en el Bajo Atrato. Ascoba, una propuesta desde el etnodesarrollo para el fortalecimiento de la apropiación territorial y la identidad cultural de afros y mestizos”. Tesis de licenciatura, Universidad Santo Tomás, Bogotá.

GMH (Grupo de Memoria Histórica). 2013. ¡Basta ya! Colombia: memorias de guerra y dignidad. Bogotá: Centro de Memoria histórica. 
Grueso, Libia. 2006. "Escenarios de colonialismo y (de) colonialidad en la construcción del Ser Negro. Apuntes sobre las relaciones de género en comunidades negras del Pacífico colombiano”. Comentario Internacional 2 (7): 145-156. https://revistas.uasb.edu.ec/index. php/comentario/article/view/136

Grueso, Libia, Carlos Rosero y Arturo Escobar. 1997. "El proceso organizativo de comunidades negras en Colombia”. Ecología Política 14: 47-64. https://www.jstor.org/stable/20742937

Hoffmann, Odile. 2002. "Conflictos territoriales y territorialidad: el caso de las comunidades afrocolombianas”. En Afrodescendientes en las Américas: trayectorias sociales e identitarias, editado por Claudia Mosquera, Mauricio Pardo y Odile Hoffmann, 351-368. Bogotá: Universidad Nacional de Colombia.

Ministerio del Interior, República de Colombia. 2017. Plan de caracterización de Consejo Comunitario de la Cuenca del Río Cacarica. Bogotá: República de Colombia.

Presidencia de la República de Colombia. 1995. Decreto 1745 del 12 de octubre, "Por el cual se reglamenta el capítulo III de la Ley 70 de 1993, se adopta el procedimiento para el reconocimiento del derecho a la propiedad colectiva de las 'Tierras de las Comunidades $\mathrm{Ne}$ gras’ y se dictan otras disposiciones”.

Restrepo, Eduardo y Axel Rojas. 2010. Inflexión decolonial: fuentes, conceptos y cuestionamientos. Popayán: Universidad del Cauca.

Rincón, Oriana, Keila Millán y Omar Rincón. 2015. “El asunto decolonial: conceptos y debates”. Perspectivas. Revista de Historia, Geografía, Arte y Cultura (3) 5: 75-95.

Rojas, John Larry. 2004. "Derecho, desplazamiento forzado interno y construcción del Estado”. El Otro Derecho 30: 135-169.

Rosero, Carlos. 2002. "Los afrodescendientes y el conflicto armado en Colombia: la insistencia en lo propio como alternativa”. En Afrodescendientes en las Américas: trayectorias sociales e identitarias, editado por Claudia Mosquera, Mauricio Pardo y Odile Hoffmann, 351-368. Bogotá: Universidad Nacional de Colombia.

Ruiz-Serna, Daniel. 2011. “Etnicidad, estado y organizaciones negras en el Bajo Atrato”. En La multiculturalidad estatalizada: indígenas, afrodescendientes y configuraciones de estado, compilado por Margarita Chaves, Mauricio Montenegro y Marta Zambrano, 169-177. Bogotá: Instituto Colombiano de Antropología e Historia. 